\section{Welcome to Geriatric Care}

\author{
Alberto Pilotto \\ E.O. Galliera Hospital, Genoa, Italy
}

When the President of the Italian Society of Geriatrics Hospital and Community (SIGOT), a prestigious and historical 30-year-old national scientific society devoted to Geriatrics, invited me to join the project to launch the new official journal of the Society, my first reaction was Geriatric Care! It will be the name of this new journal. Indeed, Geriatric Care is more than just a name of a new journal. Geriatric Care is a method in clinical practice, an effective model for the management of older people and the main objective of our work as geriatricians.

During the last three decades, relevant efforts have been done to advance in research in order to develop and validate new methods and new models of care for the clinical management of elderly subjects. Actually, important results have been obtained along the thin line of geriatric care of older people. Now is the time to implement these methods and models of geriatric medicine and share this great clinical and research experience with colleagues, researchers, students and care-givers, who face every day with the world of the aging people. According to this vision, the main aim of Geriatric Care is to stimulate debate and dissemination of knowledge in the geriatric field in order to ameliorate efficacy, effectiveness and efficiency of interventions to improve health outcomes of elderly people.

This is the main reason why Geriatric Care is a open access journal, free of charge, since the SIGOT will cover the costs of all activities related to the management and publication of the submitted manuscripts, giving
Authors a great opportunity to disseminate the results of their research and clinical practices as well as their opinions and suggestions in an open debate among different professionals devoted to the care of older people.

Geriatric Care seeks to publish peerreviewed manuscripts dealing with the Geriatric Care in different settings including, but not limited to, hospitals, residential services, nursing homes and home-care services for the elderly. Geriatric Care publishes contributions of epidemiology, pathophysiology and clinical assessment, management and treatments of the diseases of the older people, as well as health education and environmental health, hospital-residential-homecare management of the elderly including ethics, social and communication sciences, e-health and health technology assessment. Contributions on innovative topics of biological and genetics research, gender and disparity issues, as well as high-technology supports, i.e. domotics and robotics for the elderly, will be welcome as Original Articles, Review Articles, Brief Reports, Case Reports, Statement Reports and Editorials.

A reference journal needs an authoritative Editorial Board. Geriatric Care involves a group of very expert opinion leaders as Associate Editors who are actively involved both in research and in clinical practice, in agreement with the choice of Geriatric Care to give impulse to translational research. Moreover, a group of selected colleagues who are experiencing their professional skills in different countries all over the world will act as members of the International Board to give a multicolored contribution in terms of information, opinions and suggestions.

A very expert publisher like PAGEPress completed the team as a well-run full-option car ready to start for a long and thrilling journey with the warranty of fast and accurate job,
Correspondence: Alberto Pilotto, E.0. Galliera Hospital, Mura delle Cappuccine 14, 16128 Genoa, Italy.

Tel.: +39.010.5634467 - Fax: +39.010 .5634053 .

E-mail: editor-in-chief@geriatric-care.org

Key words: Editorial; Geriatric Care.

This work is licensed under a Creative Commons Attribution-NonCommercial 4.0 International License (CC BY-NC 4.0).

(C) Copyright A. Pilotto, 2015

Licensee PAGEPress, Italy

Geriatric Care 2015; 1:5635

doi:10.4081/gc.2015.5635

assured by a wide spread of publications that reach a large international audience of readers.

Just few years ago, we could not imagine that the health care needs of elderly people would have changed so rapidly and the Geriatric Care become a priority for all the Public Health Systems in the world. Indeed, National and International Health Policies are searching the magical box to guarantee an appropriate health assistance to the older populations, taking into account quality of life and preferences of the subjects as well as economic sustainability. Most probably in this process new parameters and innovative perspectives for the aging people are needed. We are convinced that further researches as well as the development of innovative solutions in Geriatric Care will be crucial to build a world that really could be inclusive of the aging populations.

Our feeling is that Geriatric Care journal will give a significant contribution to this mission.

Alberto Pilotto

Editor-in-Chief, Geriatric Care 